\title{
M-Learning: o uso de dispositivos móveis como ferramenta didáti- ca no Ensino de Química
}

\author{
M-Learning: the use of mobile devices as a didactic tool in the teaching of chemistry
}

\author{
Bruno Silva Leite \\ Universidade Federal Rural de Pernambuco - UFRPE \\ bruno.leite@dq.ufrpe.br
}

\begin{abstract}
Resumo Este trabalho pretende trazer para a discussão novas formas de utilização educativa das tecnologias da informação e comunicação, neste caso o uso das tecnologias do m-learning para o ensino de Química. A abordagem metodológica adotada foi de natureza qualitativa e a estratégia empregada foi o estudo de caso, na qual 47 alunos do ensino médio participaram de três etapas: Pesquisa com o uso do celular sobre definições de calor; Apresentação dos resultados da pesquisa através de um seminário; Resolução de um questionário avaliativo do uso do celular como ferramenta de aprendizagem. O estudo analisou como os alunos se apropriaram do celular como ferramenta de aprendizagem, avaliou o celular como ferramenta de mediação em atividades de aprendizagem e analisou as potencialidades e limitações da sua integração no processo de ensino e aprendizagem. Os resultados coletados no estudo apontam para a postura favorável dos alunos frente à utilização dos dispositivos móveis em sala de aula e novas perspectivas de pesquisa são discutidas.
\end{abstract}

Palavras-Chave: Aprendizagem móvel, Tecnologias da Informação e Comunicação, Ensinoaprendizagem, Recursos didáticos, Ensino de Química.

\begin{abstract}
This paper we aims to discuss about new ways to educative use of information and communication technologies, in this case, the use of m-learning technologies for the chemistry teaching. The methodological approach adopted was qualitative with a case study strategy, in which 47 high school students participated in three stages: research with the use of cell phone about heat definitions, presentation of research results through a seminary and solve of a questionnaire evaluation about the use of mobile phones as a learning tool. This paper analyzed how students appropriated of cell phone as a learning tool, evaluated the cell phone as a mediation tool in learning activities and analyzed the potentialities and limitations of your integration in the teaching-learning process. The results show a favorable posture of the students face to utilization of the mobile devices in classroom and new perspectives are discussed.
\end{abstract}

Keywords: M-learning, Information and Communication Technologies, Teaching-Learning, Didactic resources, Chemistry Teaching. 


\section{Introdução}

O conceito de Tecnologias da Informação e da Comunicação (TIC) é utilizado para expressar a convergência entre a informática e as telecomunicações. As TIC agrupam ferramentas informáticas e telecomunicativas como: televisão, vídeo, rádio, Internet etc. Todas essas tecnologias têm em comum a utilização de meios telecomunicativos que facilitam a difusão da informação.

Segundo Freire [1], não se deve ser um ingênuo apreciador da tecnologia. Mesmo que nela haja um enorme potencial de estímulos e desafios à curiosidade das crianças e adolescentes, há muito a se fazer para transformá-la em ferramenta de inclusão social e de desenvolvimento da cidadania em um definido projeto político-pedagógico. As atuais tecnologias disponíveis nos permitem capturar, armazenar, organizar, pesquisar, recuperar e transmitir a informação de nosso interesse com extrema eficácia [2]. Temos também ferramentas tecnológicas que nos permitem analisar, avaliar e transformar essa informação em conhecimento, colocando-as a bom uso em nossos processos tanto de entendimento e compreensão da realidade como de tomada de decisão e ação. Enfim, as TIC criaram novos espaços de construção do conhecimento. Agora, além da escola, também a residência, a empresa e os ambientes sociais podem se tornar espaços educativos.

De acordo com Kenski [3], as TIC proporcionam um novo tipo de interação do professor com os alunos, possibilitando a criação de novas formas de integração do professor com a organização escolar e com outros professores. O uso das diversas ferramentas disponíveis tornase aliado do processo de ensino-aprendizagem [4, 5], conforme afirma Giordan [6], devemos aproveitar essa oportunidade de acesso a diferentes fontes de informações e conhecimentos trazidos pela comunicação mediada por redes de computadores. A incorporação das TIC na educação tem consequências tanto para a prática docente como para os processos de aprendizagem. Contudo, a simples incorporação ou o uso em si das TIC não geram, inexoravelmente, processos de inovação e melhoria do ensino-aprendizagem, na verdade, são determinados usos específicos das TIC que parecem ter a capacidade de desencadear esses processos.

Sabemos que a prática pedagógica do professor em sala de aula necessita de constantes atualizações, e para isso o computador, o Tablet e o celular, podem contribuir no processo de ensino-aprendizagem. A utilização da internet deve, segundo Giordan [7], tomar como pressuposto a formação de seus professores e da equipe pedagógica dentro da própria escola.

Segundo Prensky [8] as tecnologias da informação e comunicação possibilitaram o livre acesso à informação a uma nova geração de aprendizes, os nativos digitais. Para
Prensky [8] existem dois tipos de usuários das TIC: aqueles provenientes de uma cultura anterior, organizada basicamente em torno dos textos impressos, que ele denomina "imigrantes digitais", que precisaram adaptar-se às novas modalidades de interação e comunicação digital, e o segundo tipo, descrito por Prensky [8], os "nativos digitais", que desenvolvem uma vida online, para os quais o ciberespaço é parte constituinte do cotidiano. Um aspecto diferencial é o fato de que o nativo frequentemente atua como produtor de conteúdos e também como formador.

O educador, antes centro das informações e dos conhecimentos, adquire novas habilidades de mediador ou orientador e, no exercício de sua profissão, passa a considerar: o perfil dos alunos, seus conhecimentos prévios, suas preferências de aprendizagem, seus estilos cognitivos e os conteúdos e métodos de como aplicar e/ou transmitir conteúdos embasados por várias teorias de aprendizagem. Segundo Coll e Monereo [4], o acesso do professorado e dos alunos às TIC é uma condição necessária que ainda está longe de ser cumprida. O impacto das TIC na educação é, na verdade, um aspecto particular de um fenômeno muito mais amplo, relacionado com o papel dessas tecnologias na sociedade atual. A Internet não é apenas uma ferramenta de comunicação e de busca [4], além disso, ela constitui um espaço para o aprendizado e para a ação educacional.

Este trabalho busca discutir as possibilidades da aprendizagem móvel em contribuir para o processo de ensino e aprendizagem e estratégias que possam ser utilizadas. Analisar a utilização dos dispositivos móveis por alunos durante a aula.

\subsection{Construtivismo, Construcionismo e Conectivismo}

Segundo Piaget [14], construtivismo é o processo de aprendizagem do indivíduo de acordo com interações e perturbações do conhecimento em seu meio, considerando, como critério, a idade do indivíduo relacionada ao contexto. Piaget acredita que a aprendizagem construtivista necessita que o aluno passe pelo processo de: perturbação do equilíbrio dos seus conceitos; conservação, que é a compensação da modificação simultânea do objeto; e assimilação x acomodação do mesmo conceito. No final do processo evolutivo da aprendizagem, o indivíduo se torna autônomo, questionador, adaptativo e interativo no seu meio. A teoria construtivista de Piaget elucida que 
cada indivíduo possui um mecanismo de aprendizagem próprio antes de ir à escola. A construção do conhecimento resulta da interação social, onde a educação se baseia num conjunto de problemas motivadores e realistas.

O construtivismo tem sido uma das abordagens teóricas mais utilizadas para orientar o desenvolvimento de materiais didáticos informatizados. Nessa perspectiva, o usuário $^{1}$ constrói representações por meio de sua interação com a realidade, que irão constituir seu conhecimento, processo insubstituível e incompatível com a ideia de que o conhecimento possa ser adquirido ou transmitido. Uma das características do construtivismo em ambientes virtuais é o fato da aprendizagem ser controlada pelo próprio usuário, assim esse ambiente oferece ao aluno ferramentas de construção e a possibilidade de interação com a realidade. O computador é usado como ferramenta para gravar, analisar e comunicar interpretações da informação entre os participantes. O usuário deverá construir seu próprio banco de informações e assumir a responsabilidade pelo gerenciamento das tarefas de aprendizagem.

O papel do professor, na abordagem construtivista, aproxima-se de uma concepção de profissional que facilita a construção de significados por parte do aluno nas suas interpretações do mundo. Para que possa ajudar o aluno, o facilitador pedagógico, primeiramente, deverá possuir um entendimento claro da construção de conhecimento enquanto processo dinâmico e relacional, advindo da reflexão conjunta sobre o mundo real. Deverá possuir base teórica consistente, um claro conhecimento do objetivo da aprendizagem e da metodologia a ser utilizada, assim, como do processo de avaliação de acordo com a visão construtivista de conhecimento. Cabe ressaltar que com base em orientações construtivistas, podemos dar ênfase a necessidade de uma formação do professor voltada também às tecnologias, no caso do Google+, a aprendizagem que esse pode proporcionar a professores e alunos.

O construcionismo tem suas raízes no trabalho de Seymour Papert [15] e seu pressuposto teórico vai além da afirmação de que o conhecimento é construído pelo indivíduo, mas que isso acontece especialmente quando o mesmo está engajado na construção de algo externo.

A construção do conhecimento através do computador tem sido denominada por Papert de Construcionismo [15]. Ele usou esse termo para mostrar um outro nível de construção do conhecimento, que acontece quando o aluno constrói um objeto de seu interesse, como uma obra de arte, um relato de experiência ou um programa de computador. Na noção de construcionismo de Papert [15] existem duas ideias que contribuem para que esse tipo de construção do conhecimento seja diferente do construtivismo de Piaget.

- Primeiro, o aprendiz constrói alguma coisa, ou seja, é o aprendizado através do fazer, do "colocar a mão na massa".

- Segundo, o fato de o aprendiz estar construindo algo do seu interesse e para o qual ele está bastante motivado. O envolvimento afetivo torna a aprendizagem mais significativa.

Para Papert [15], a aprendizagem ocorre na interação entre indivíduo e o mundo, porém o contato com o mundo é facilitado com um computador e uma linguagem de programação.

Siemens [16] discute as limitações do behaviorismo, cognitivismo e construtivismo como teorias de aprendizagem, porque elas não abordam a aprendizagem que ocorre fora das pessoas (isto é, aprendizagem que é armazenada e manipulada através da tecnologia) dentro das organizações. A tabela 1 indica as diferenças apresentadas por Siemens [17] entre as teorias de aprendizagem.

${ }^{1} \mathrm{O}$ termo usuário neste contexto refere-se a professor e/ou aluno. 


\begin{tabular}{|c|c|c|c|c|}
\hline Propriedade & Behaviorismo & Cognitivismo & Construtivismo & Conectivismo \\
\hline $\begin{array}{l}\text { Como ocorre a } \\
\text { aprendizagem? }\end{array}$ & $\begin{array}{c}\text { Caixa-preta } \\
\text { Foco principal o } \\
\text { comportamento } \\
\text { observável }\end{array}$ & $\begin{array}{r}\text { Estruturado, } \\
\text { Computacional }\end{array}$ & $\begin{array}{l}\text { Significado social, } \\
\text { criado por cada aluno } \\
\text { (pessoal) }\end{array}$ & $\begin{array}{c}\text { Distribuídos dentro } \\
\text { de uma rede social, } \\
\text { tecnologicamente } \\
\text { avançada, } \\
\text { reconhecendo e } \\
\text { interpretando } \\
\text { padrões }\end{array}$ \\
\hline $\begin{array}{c}\text { Que fatores } \\
\text { influenciam a } \\
\text { aprendizagem? }\end{array}$ & $\begin{array}{l}\text { Natureza da } \\
\text { recompensa, a } \\
\text { punição, os } \\
\text { estímulos }\end{array}$ & $\begin{array}{l}\text { Esquema } \\
\text { existente, } \\
\text { experiências } \\
\text { anteriores } \\
\end{array}$ & $\begin{array}{l}\text { Engajamento, } \\
\text { participação, social, } \\
\text { cultural }\end{array}$ & $\begin{array}{c}\text { Diversidade da rede, } \\
\text { força dos laços }\end{array}$ \\
\hline $\begin{array}{l}\text { Qual o papel da } \\
\text { Memória? }\end{array}$ & $\begin{array}{l}\text { A memória é “a } \\
\text { fiação” de } \\
\text { experiências } \\
\text { repetidas - onde } \\
\text { recompensa e } \\
\text { punição são mais } \\
\text { influentes } \\
\end{array}$ & $\begin{array}{l}\text { Codificação, } \\
\text { armazenamento, } \\
\text { recuperação }\end{array}$ & $\begin{array}{c}\text { Conhecimento prévio } \\
\text { remixado para o } \\
\text { contexto atual }\end{array}$ & $\begin{array}{c}\text { Padrões adaptativos, } \\
\text { representando o } \\
\text { estado atual, } \\
\text { existentes em redes }\end{array}$ \\
\hline $\begin{array}{l}\text { Como ocorre a } \\
\text { transferência? }\end{array}$ & Estímulo, resposta & $\begin{array}{l}\text { Duplicando } \\
\text { constrói } \\
\text { conhecimento de } \\
\text { "conhecedor" }\end{array}$ & Socialização & $\begin{array}{l}\text { Conectando } \\
\text { (adicionando) links }\end{array}$ \\
\hline $\begin{array}{l}\text { Que tipos de } \\
\text { aprendizagem } \\
\text { são mais bem } \\
\text { explicados por } \\
\text { esta teoria? }\end{array}$ & $\begin{array}{l}\text { Baseado em } \\
\text { tarefas de } \\
\text { aprendizagem }\end{array}$ & $\begin{array}{l}\text { Raciocínio, } \\
\text { objetivos claros, } \\
\text { resolução de } \\
\text { problemas }\end{array}$ & $\begin{array}{l}\text { Social, vago ("mal } \\
\text { definidos") }\end{array}$ & $\begin{array}{c}\text { Aprendizagem } \\
\text { complexa, núcleo } \\
\text { em rápida mudança, } \\
\text { diversas fontes de } \\
\text { conhecimento }\end{array}$ \\
\hline
\end{tabular}

Tabela 1: Diferenças entre teorias de aprendizagem.

O conectivismo (ou aprendizagem distribuída) é proposto como uma teoria mais adequada para a era digital, quando a ação é necessária sem aprendizagem pessoal, utilizando as informações fora do nosso conhecimento primário. É também considerada como a terceira geração de pedagogia da educação a distância [18].

O conectivismo é guiado pela noção de que as decisões são baseadas em princípios que estão mudando rapidamente. Continuamente se está adquirindo novas informações. Segundo Siemens [16] a habilidade de realizar distinções entre a informação importante e não importante resulta ser vital. Também é crítica a habilidade de reconhecer quando uma nova informação altera um ambiente baseado nas decisões tomadas anteriormente. Os princípios do conectivismo podem ser destacados a seguir:

- Aprendizagem e conhecimento dependem da diversidade de opiniões;

- Aprendizagem é um processo de conectar "nós" (links) ou fontes de informações especializadas;

- Aprendizagem pode residir em dispositivos não humanos;

- A capacidade de saber mais é mais crítica que aquela que se sabe em um dado momento;

- Alimentação e mantimento das conexões é necessária para facilitar a aprendizagem contínua;

- Habilidade de ver conexões entre áreas, ideias e conceitos é uma habilidade chave;

- Atualização (conhecimento preciso e atual) é a intenção de todas as atividades conectivistas de aprendizagem;

- A tomada de decisões é, em si mesma, um processo de aprendizagem. $O$ ato de escolher o que aprender e o significado da informação que se recebe, é visto através da lente de uma realidade em mudança. Uma decisão correta hoje, pode estar equivocada amanhã, devido a alterações no ambiente informativo que afeta a decisão.

O conhecimento que reside em uma base de dados deve estar conectado com pessoas precisas no contexto adequado para que possa ser classificado como aprendi- 
zagem [16]. O ponto de partida do conectivismo é o indivíduo. Segundo Siemens [16] o conectivismo apresenta um modelo de aprendizagem que reconhece os movimentos tectônicos em uma sociedade onde a aprendizagem não é mais uma atividade interna e individual. Mattar [19] acredita que o conectivismo deve ser considerado uma versão atualizada do construtivismo, entendida como uma filosofia geral de educação para a era digital.

\subsection{Aprendizagem Móvel}

O impacto do uso de tecnologias de comunicações móveis em ambientes de aprendizagem foi examinado empiricamente por vários estudos [20,21], na qual concluíram que a disponibilidade de reforço e acessibilidade das redes de informação, envolvem os alunos na aprendizagem relacionadas com atividades em diversos locais físicos e melhoram a comunicação e aprendizagem colaborativa em sala de aula. A Aprendizagem Móvel (Mobile Learning ou m-learning) é considerada um paradigma emergente, relacionado com três tecnologias: poder de computação do ambiente, comunicação do ambiente e desenvolvimento de interfaces inteligentes do usuário [22].

De acordo com as definições encontradas na literatura, o Mobile é o emprego de tecnologias específicas que diferenciam a aprendizagem móvel de outras aprendizagens eletrônicas (e-learning) [22]. Sua definição envolve a utilização de equipamentos de informação e comunicação móveis e sem fio em processos de aprendizagem, mas não se resume a isso. A definição de Mobile Learning pode ser ampliada para qualquer tipo de aprendizagem que ocorre quando o estudante não está em um local estático e estipulado, ou no momento em que a aprendizagem acontece quando o estudante "tira" vantagem das oportunidades de aprendizagem oferecidas por tecnologias móveis. Entretanto, não podemos conjecturar que usar um celular, por exemplo, para realizar uma atividade durante a aula de Química caracteriza o m-learning.

O Mobile Learning aproveita as potencialidades de dispositivos móveis (celular, PDA, PSP, Pocket PC, Tablet, PC, Netbook) usufruindo de oportunidades de aprendizagem através de diferentes contextos e tempos. Pensando em mobilidade numa perspectiva do aluno, o $m$-learning se torna mais importante, visto que a aprendizagem pode ocorrer em qualquer ambiente, quer seja na escola, na universidade, em casa, em lugares públicos. Segundo Bartholo et al. [23] a utilização do m-learning permite a alunos fazerem uma revisão para o exame no ônibus a caminho da escola, aos médicos atualizarem seus conhecimentos médicos enquanto circulam por hospitais, a estudantes de idioma melhorarem habilidades de idioma enquanto viajam para outros países. Outra carac- terística associada ao m-learning é a ubiquidade, isto é, a possibilidade da aprendizagem ocorrer em qualquer lugar. Os utilizadores dos dispositivos móveis usam e os levam para todo lado, utilizam constantemente em todos os momentos da vida e numa variedade de situações e agora podem utilizá-los para sua aprendizagem.

As vantagens que a aprendizagem móvel permite são inúmeras, destacamos algumas: a possibilidade de interação (professor-aluno, aluno-aluno); desenvolver experiências de aprendizagem individual e trabalho coletivo (os alunos podem atuar em uma mesma tarefa mesmo em locais distintos); a portabilidade (o celular ou o smartphone, por exemplo, são mais leves que um PC ou notebook); realizar aprendizagem informal, a flexibilidade e autonomia aos estudantes; além da possibilidade de aumentar a autoestima e autoconfiança. Os professores podem através do m-learning fornecer aos alunos conteúdos a qualquer hora, estes podem acessar os conteúdos de química quando necessário, facilitando aos mesmos uma aprendizagem pela comodidade e rapidez de acesso a informação, por se tratar de um dispositivo pessoal com grande acolhimento e por estar sempre a "mão".

Contudo, o m-learning não pode ser necessariamente sinônimo de tecnologia de última geração. Devemos utilizar metodologias adequadas ao contexto na qual se inserem. $\mathrm{O}$ professor precisa se apropriar das questões teóricas na vinculação com as especificidades da tecnologia. Nesse sentido o professor poderá ser capaz de identificar os limites e potencialidades dessa tecnologia.

Prensky [24] foi um dos primeiros a propor o uso do celular na sala de aula. Entretanto, observou-se que o celular, no contexto do uso das TIC na educação, embora seja mais adotado pela população, é proibido na maioria das salas de aula. É preciso perceber que esses dispositivos potenciam uma ampla variedade de oportunidades para melhorar a aprendizagem, através da flexibilidade do tempo e do lugar em que ela pode ocorrer.

Os dispositivos móveis tem grande potencial para promover a aprendizagem. Nesse sentido o celular, por exemplo, pode contribuir para o processo de aprendizagem dos estudantes, diferente do que muitos professores acreditam que o celular distrai e atrapalha a aula. No entanto, é necessária uma profunda reflexão sobre as contribuições que esta tecnologia provoca. A aprendizagem móvel pode ser empregada no ensino de Química dada a sua facilidade de acesso a qualquer momento e em qualquer lugar. 


\subsection{Aprendizagem 2.0}

No contexto da sociedade do conhecimento, as tecnologias de uso educativo - já são implementadas para o ensino presencial ou a distância - se tem convertido em um suporte fundamental para a instrução, beneficiando um universo cada vez mais amplo de pessoas. Esta associação entre tecnologia e educação não somente gera melhoras de caráter quantitativo (possibilidade de ensinar a mais estudantes), mas principalmente de ordem qualitativa (os educandos encontram na Internet novos recursos e possibilidades de enriquecer seu processo de aprendizagem). A educação tem sido uma das disciplinas mais beneficiadas com a "interferência" das novas tecnologias, especialmente as relacionadas com a Web 2.0.

Segundo Johnson [25], existem três tipologias diferentes de aprendizagem, contudo o foco que Johnson propõe nesta aprendizagem é na Internet:

1) Aprender fazendo: para este tipo de aprendizagem a utilização das ferramentas permitem ao estudante e/ou professor a leitura e a escrita na Web, baseados no princípio de "ensaio-erro".

2) Aprender interatuando: além da escrita oferecem a possibilidade de intercâmbio de ideias com os demais usuários da internet. A ênfase é aprender interatuando com os demais.

3) Aprender buscando: um dos exercícios de um trabalho, pesquisa ou outra atividade é a busca de fontes que ofereçam informação sobre o tema que se abordará. Esse processo de investigação, seleção e adaptação termina ampliando e enriquecendo o conhecimento de quem o realiza. Em um ambiente de grande quantidade de informação disponível, resulta fundamentalmente aprender como e onde buscar conteúdos educativos.

Lundvall [26] acrescenta a esta taxonomia um quarto tipo de aprendizagem, que representa o valor essencial das ferramentas Web 2.0 e que está baseado na ideia de compartilhar informações, conhecimentos e experiências:

4) Aprender compartilhando: o processo de intercâmbio de conhecimentos e experiências permitem aos educandos participar ativamente de uma aprendizagem colaborativa. Ter acesso à informação, não significa aprender, por isso, a criação de instâncias que promovam compartilhar objetos de aprendizagem e enriqueçam significativamente o processo educativo.

Nesta podemos observar uma das características dos ambientes pessoais de aprendizagem, que instiga a busca por criar ambientes (instâncias) que promovam o compar- tilhamento não somente de objetos de aprendizagem, mas da própria aprendizagem ao longo de sua vida.

\subsection{Pensando em Calor}

O conhecimento sobre a natureza do calor durante séculos estimulou diversos filósofos, cientistas, físicos e Químicos. Uma discussão interessante a esse respeito é apresentada por Oliveira e Santos [9] sobre a Energia e a Química. Segundo Mortimer e Amaral [10] o calor não tem o mesmo significado na ciência e na linguagem comum. Na ciência, ao contrário do que ocorre na vida cotidiana, não admitimos a existência de dois processos de transferência de energia - o do calor e o do frio -, mas apenas de um, o do calor [10].

Podemos entender Calor como a energia transferida de um objeto mais quente para um objeto mais frio, isto é, a energia transferida em consequência de uma diferença de temperatura. O calor eleva a temperatura dos objetos vizinhos, se definirmos, por exemplo, a reação como o sistema e todo o resto como a vizinhança, a energia em forma de calor será transferida do sistema para a vizinhança. Calor é um termo comum que em termodinâmica tem um significado especial.

\subsection{Web 2.0}

A $W e b 2.0$ é a segunda geração de serviços online e caracteriza-se por potencializar as formas de publicação, compartilhamento e organização de informações, além de ampliar os espaços para a interação entre os participantes do processo. O termo Web 2.0, da autoria de Tim O'Reilly [11], surgiu numa sessão de brainstorming no MediaLive International em outubro de 2004 no que fez as seguintes considerações: “A $W e b 2.0$ é a mudança para uma Internet como plataforma, e um entendimento das regras para obter sucesso nessa nova plataforma. Entre outras, a regra mais importante é desenvolver aplicativos que aproveitem os efeitos de rede para se tornarem melhores quanto mais são usados pelas pessoas, aproveitando a inteligência coletiva" [11].

A $W e b 2.0$ se refere não apenas a uma combinação de técnicas informáticas, mas também a um determinado período tecnológico, a um conjunto de novas estratégias mercadológicas e a processos de comunicação mediados pelo computador. De acordo com Primo [12], a Web 2.0 tem repercussões sociais importantes, que potencializam processos de trabalho coletivo, de troca afetiva, de produção e veiculação de informações, na (re)construção do conhecimento apoiada pelos recursos tecnológicos.

A primeira geração da Internet teve como principal 
atributo a enorme quantidade de informação disponível e a que todos podíamos acessar. No entanto, o papel do utilizador nesses cenários era o de mero espectador da ação que se passava na página que se visitava, não tendo autorização para alterar ou reeditar o seu conteúdo. Se na primeira geração da web os sites eram trabalhados como unidades isoladas, passa-se agora para uma estrutura integrada de funcionalidades e conteúdos. Com a introdução da Web 2.0 as pessoas passaram a produzir os seus próprios documentos e a publicá-los automaticamente na rede, sem a necessidade de grandes conhecimentos de programação e de ambientes sofisticados de informática.

Cobo e Pardo [13] propõem ordenar a Web $2.0 \mathrm{em}$ quatro linhas fundamentais: Redes sociais que descreve todas as ferramentas desenhadas para a criação de espaços que promovam ou facilitem a construção de comunidades de intercâmbios sociais; Conteúdos que fazem referências as ferramentas que favorecem a leitura e a escrita online, assim como sua distribuição e intercâmbio; Organização Social e inteligência da informação as ferramentas e recursos para marcar, organizar e indexar, facilitando a ordem e armazenamento da informação, assim como de outros recursos disponíveis na rede; Aplicações e serviços (Mashups) esta classificação inclui inúmeras ferramentas, softwares, plataformas online e diversos recursos criados para oferecer serviços ao usuário.

Além de novas ou potencializadas formas de publicação e circulação de informações, a Web 2.0 potencializa a livre criação e organização distribuída de informações compartilhadas através de associações mentais. Considerando tais premissas, defende-se que o estudo da Web 2.0 deve levar em conta não apenas os aspectos tecnológicos e de conteúdo, mas também as interações sociais quanto a sua forma: o aspecto relacional [2].

Infelizmente muitos professores não utilizam as tecnologias da Web 2.0 com enfoque de ensinar utilizando essas tecnologias. E nem algumas universidades se preocupam com a formação desses professores para que utilizem as tecnologias no processo educacional. O problema que enfrentamos hoje não é como disponibilizar mais informações, mais conteúdo, mas em aprender a identificar quais, por que e para que necessitamos, de modo que saibamos localizá-los, avaliá-los com sentido crítico e adaptarmos a nossa necessidade de formação e comunicação. A figura 1 sintetiza resumidamente a evolução da Web e a chegada da Web 2.0 em uma linha de tempo ilustrada.

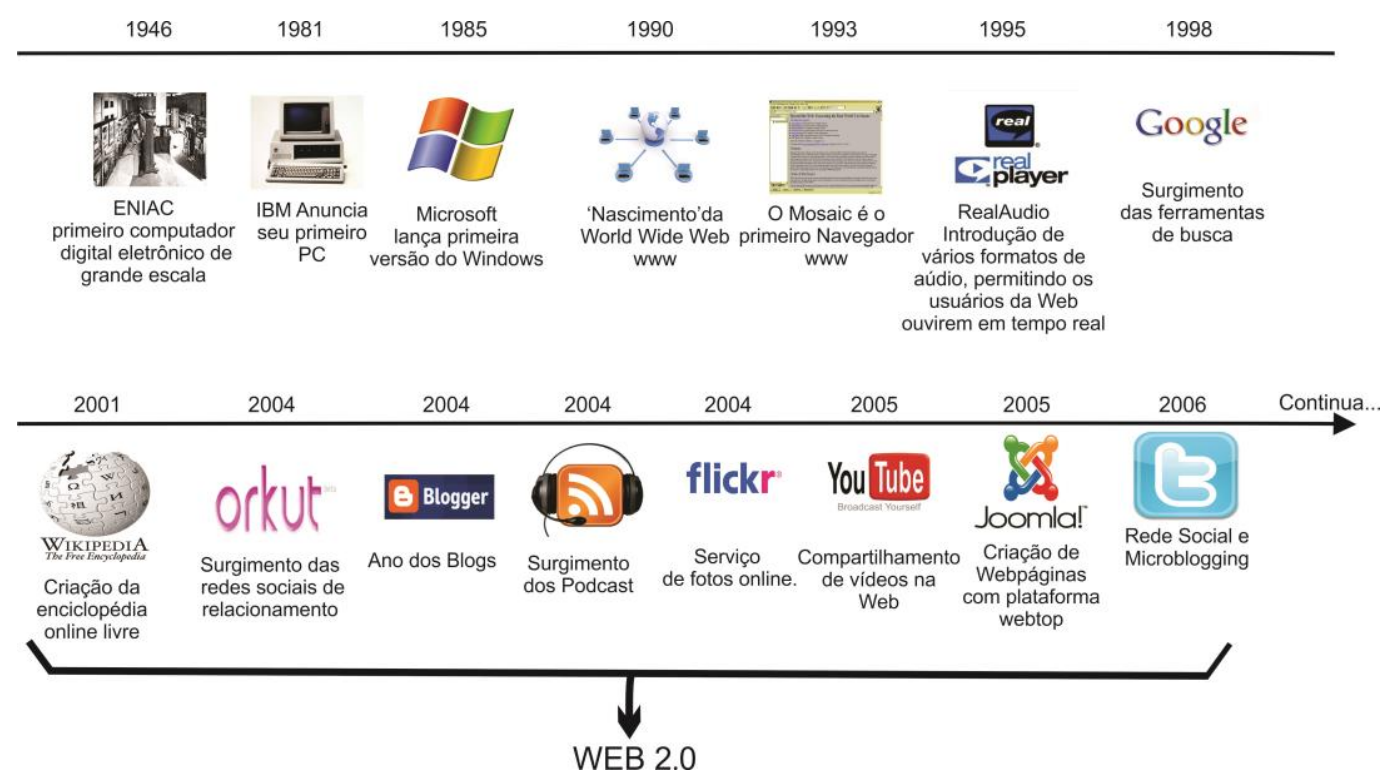

Figura 1: Evolução da web.

Cabe ressaltar, que a $W e b 2.0$ propicia maior interatividade, tornando o ambiente presencial e virtual mais dinâmico, e os educadores da atualidade não podem deixar de utilizar tais recursos, uma vez que impacta no aprendizado dos usuários, proporcionando o desenvolvimento de habilidades e competências na utilização de recursos digitais, através da interatividade entre os seus participantes. O trabalho do professor é fundamental na utilização de ferramentas da Web 2.0 até porque a qualidade educativa desses meios de ensino depende, mais do que de suas características técnicas, do uso ou exploração didática que realiza o docente e do contexto em que se desenvolve. 
Nesse estudo, foi elaborada uma atividade com o $\mathrm{m}$ learning na qual os alunos pesquisaram na Web 2.0 definições sobre calor e exploraram alguns recursos da $\mathrm{Web}$ 2.0 e dos dispositivos móveis.

\section{Metodologia}

Para o desenvolvimento deste trabalho levamos em consideração a pesquisa qualitativa. Segundo Lüdke e André [27], um modelo qualitativo descreve, compreende e explica, trabalhando nessa ordem. Nesse sentido o trabalho foi desenvolvido como um estudo de caso, a fim de melhor elucidar a utilização do m-learning como uma ferramenta didática no processo de ensino e aprendizagem de Química.

\subsection{Universo da Investigação}

Para a atividade proposta somaram-se ao total 47 alunos que participaram da pesquisa divididos em dez (10) grupos de alunos de duas turmas $\left(2^{\circ}\right.$ ano $\mathrm{A} \mathrm{e} 2^{\circ}$ ano $\left.\mathrm{B}\right)$ do ensino médio da rede privada de ensino, localizados na cidade de Jaboatão dos Guararapes. O tema abordado para aplicação da atividade foi Calor para todos os grupos. Em cada turma foram divididos os grupos de um (1) até cinco (5). Para melhor elucidar os grupos classificamos em: A1, A2, A3, A4 e A5 para os alunos do $2^{\circ}$ ano $\mathrm{A}$ e B1, B2, B3, B4 e B5 para a turma do $2^{\circ}$ ano B. A divisão do número de alunos por grupos não foi homogênea, deixando os alunos livres para formarem seus grupos, na quantidade estipulada (cinco grupos por turma). Desta forma obtivemos a seguinte divisão: grupo $\mathrm{A} 1 \mathrm{com}$ três $(\mathrm{A} 1=03) ; \mathrm{A} 2$ com cinco $(\mathrm{A} 2=05) ; \mathrm{A} 3=08 ; \mathrm{A} 4=05$; $\mathrm{A} 5=04 ; \mathrm{B} 1=05 ; \mathrm{B} 2=03 ; \mathrm{B} 3=05 ; \mathrm{B} 4=05 ; \mathrm{B} 5=04$.

Os alunos participantes dos grupos A1, A2, B1 e B2 foram instruídos para pesquisarem definições de calor em artigos e em blogs, os grupos A3, A4, B3, e B4 pesquisaram em artigos e vídeos com definições de calor e os grupos A5 e B5 ficaram livres para pesquisarem definições de calor em outros recursos da Web 2.0.

Os grupos A1, A2, A3, A4 e A5 continham ao total 25 alunos, os grupos B1, B2, B3, B4 e B5 tiveram a participação de 22 alunos. Esses alunos encontravam-se dentro de uma faixa etária de 14 a 16 anos.

\subsection{Etapas da Investigação}

A atividade foi dividida em três momentos, o primeiro consta da pesquisa utilizando os dispositivos móveis (figura 2). Com o objetivo de abordar a termoquímica o professor da disciplina realizou uma atividade com os dispositivos móveis dos alunos, na qual solicitou que esses pesquisassem definições de calor. Esta pesquisa tinha o intuito de auxiliar os alunos no entendimento do conceito de calor, dentro de uma perspectiva cotidiana, bem como numa perspectiva científica. A orientação dada pelo professor para pesquisarem em artigos reflete a importância das pesquisas que foram e que estão sendo desenvolvidas sobre a temática. No caso dos blogs, Barro et al. [28] afirmam que "Os blogs podem ser utilizados com diversos propósitos educacionais em diversas disciplinas e diferentes níveis de escolaridade devido à sua característica de ferramenta flexível que não apresenta um limite de utilização", justificando a escolha desta ferramenta para a pesquisa. Quanto aos vídeos Ferrés [29] acredita que um bom vídeo pode servir para introduzir um novo assunto, para despertar a curiosidade, a motivação para novos temas. Nesta atividade a pesquisa pelo vídeo infere na introdução de um novo assunto.

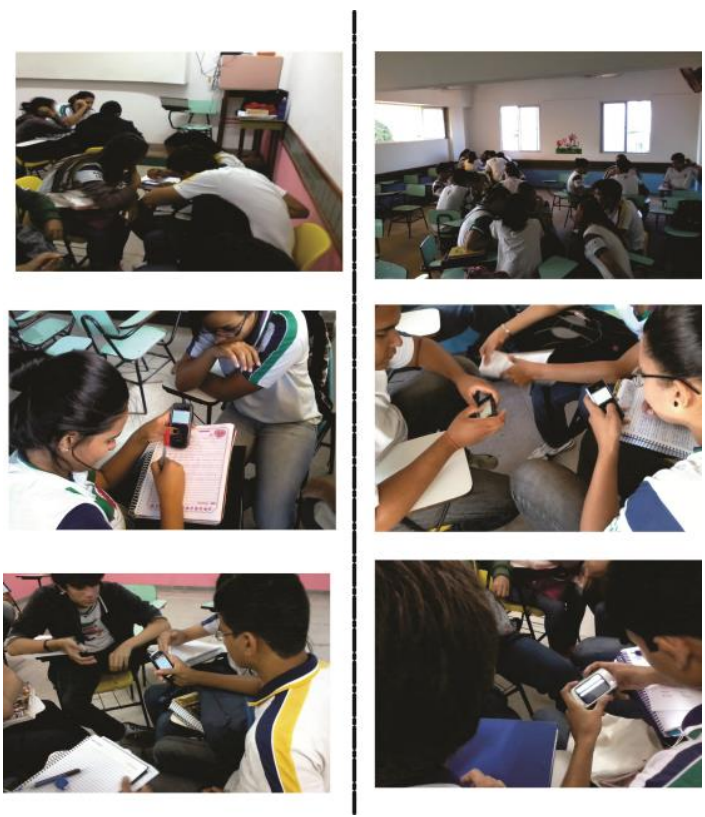

Figura 2: Utilização dos dispositivos móveis pelos alunos.

O segundo momento da atividade os alunos apresentaram suas pesquisas para a turma, na forma de seminário, elucidando sobre o tema pesquisado. Nesse sentido, foram observados pressupostos da aprendizagem 2.0 [25, 26] na apresentação dos seminários, além das premissas do conectivismo [16] como a habilidade de realizar distinções entre a informação importante e não importante, identificando as tomadas de decisões [16] desses alunos.

Por fim o terceiro momento consistiu na resolução do questionário. As respostas do questionário, quando subjetivas, foram apresentadas conforme escrito pelos alunos, preservando-se erros de redação de texto etc. ainda, eliminaram-se os nomes e dados que poderiam identificar os sujeitos. 


\subsection{Instrumentos da Pesquisa}

O questionário constou de doze (12) perguntas objetivas e subjetivas. Esse questionário buscou verificar a utilização do celular como ferramenta de aprendizagem, as contribuições durante o trabalho, o nível de conhecimento gerado após a pesquisa, além de outros aspectos quanto à pesquisa com o celular. Perguntas do questionário: Pergunta 1: Qual o grupo? Pergunta 2: Todos no grupo têm celular? ( ) Sim, ( ) Não. Quantos têm? Pergunta 3: Quantos celulares têm acesso à internet no grupo? ( ) Wi-fi, ( ) 3G, ( ) Wi-fi e 3G. Pergunta 4: Qual(is) aparelho(s) utilizado(s) na pesquisa? Pergunta 5: O que você mais faz com seu celular? ( ) Ligações, ( ) Tirar fotos, ( ) Acessar redes sociais (facebook, twitter, etc.), ( ) Enviar torpedos SMS, ( ) Jogar, ( ) Ver vídeos, ( ) Ouvir músicas, ( ) Outros. Pergunta 6: Você já tinha utilizado o celular para estudar? ( ) Não, ( ) Sim. Como? Pergunta 7: Sobre o que você pesquisou? Pergunta 8: Como foi sua pesquisa? Fale sobre os pontos positivos e negativos da pesquisa. Houve dificuldade em realizar a atividade? Pergunta 9: Qual(is) a(s) fonte(s) pesquisada(s)? Pergunta 10: Você aprendeu com sua pesquisa? ( ) Não, ( ) Sim. Justifique sua resposta. Pergunta 11: O celular como ferramenta de aprendizagem, em sua opinião: ( ) pode permitir a aprendizagem em qualquer lugar, () deixa a aula mais interessante. ( ) não ajuda a entender o conteúdo, ( ) outros. Pergunta 12: O que você achou de pesquisar com o celular?

\section{Resultados e discussão}

Na presente seção, apresentamos os resultados alcançados durante o processo de investigação da pesquisa. Primeiramente os resultados da análise dos questionários aplicados aos alunos, que descrevem dentre outros, as fontes investigadas pelos alunos; quais funções dos dispositivos móveis mais utilizadas pelos mesmos; a opinião desses sobre sua aprendizagem no uso do celular. Ao final uma discussão sobre a apresentação dos seminários dos alunos em sala de aula são discutidos.

\subsection{Análise do Questionário}

Os dados são apresentados primeiro nos questionamentos coletivos (perguntas 1, 2, 3, 4, 5, 7 e 9), em seguida das respostas individuais (perguntas $6,8,10,11$, e 12) e ao final destacamos uma síntese das semelhanças e/ou diferenças entre algumas respostas em relação ao questionário aplicado. As diferentes respostas analisadas podem ser avaliadas como benéficas, haja vista a possibilidade de se discutir sobre a diversidade das respostas para a mesma pergunta.

Ao primeiro questionamento (“Qual o grupo?”) visava organizar o questionário por grupo e classificar quanto ao tipo de pesquisa realizada (Artigos, blogs, vídeos, sites, etc.). Com o intuito de conhecer o perfil destes alunos em relação à posse de dispositivos móveis ("Todos no grupo têm celular?"), observou-se que $93,61 \%$ têm celular, e que destes alunos $9,1 \%$ dos celulares têm acesso à internet apenas via wi-fi, $36,36 \%$ via $3 \mathrm{G}$ e $13,63 \%$ possuem acesso à internet via wi-fi e $3 \mathrm{G}$ como opção no mesmo aparelho, desses dados observou-se que 40,91\% dos dispositivos móveis dos alunos não têm nenhum tipo de acesso à internet. É importante ressaltar que em cada grupo havia dispositivos móveis com acesso à internet, ou via wi-fi ou $3 \mathrm{G}$ ou wi-fi e $3 \mathrm{G}$, para garantir que todos participassem das atividades, numa perspectiva construtivista, na qual o engajamento, a participação, contribuiriam com a aprendizagem [16].

Os aparelhos utilizados na pesquisa realizada pelos alunos foram de diversas marcas e estilos, alguns grupos utilizaram celulares de última geração (iPhone e Samsung Galaxy, por exemplo) bem como aparelhos de baixo custo (nomeados pelos próprios estudantes de "xingling", fazendo menção a origem do aparelho ser chinesa). Quando questionados sobre "O que você mais faz com seu celular", além da função de ligar, observou-se que estes alunos têm preferência em utilizar os dispositivos móveis para ouvir música, a figura 3 destaca essas escolhas.

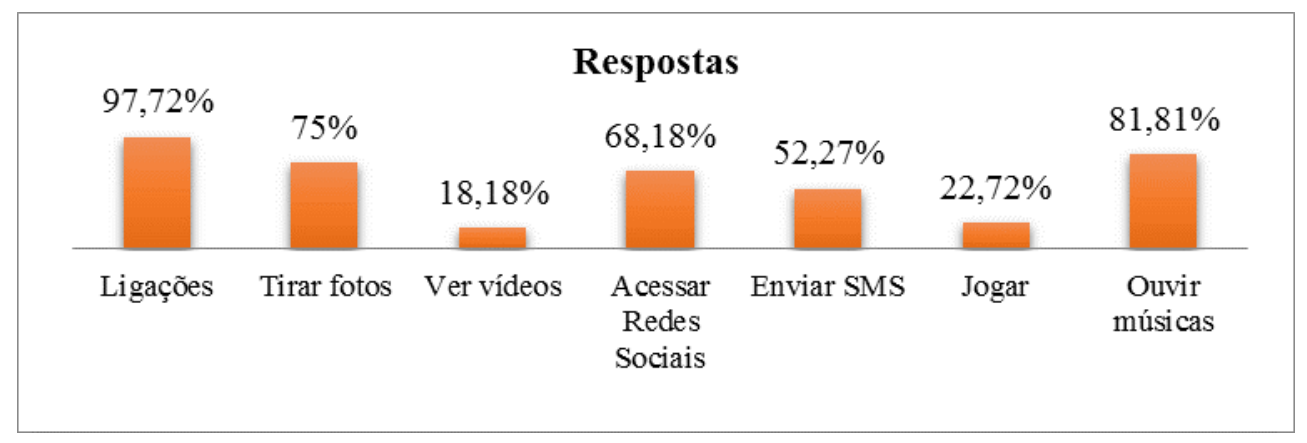

Figura 3: Gráfico das preferências dos alunos quanto ao uso do celular. 
Do questionamento sobre o uso do celular para estudar ("Você já tinha utilizado o celular para estudar?"), $68,18 \%$ nunca tinha utilizado o celular para estudar. Alguns justificam sua resposta: "Nunca tive uma oportunidade" e "O professor não deixa que use", um dos alunos ainda destaca que "Essa foi a primeira experiência que tive em aula". Infelizmente nesses dados é comprovado que o uso do computador nas escolas como ferramenta de aprendizagem é incipiente. Dos alunos que já haviam utilizado o celular para estudar $(31,82 \%)$ alguns dos motivos são descritos como: "tenho um pouco de dificuldade para aprender então gravo meu estudo e boto fones de ouvido". Este estudante utiliza o recurso do gravador como uma ferramenta que auxilia no seu aprendizado, após gravar a aula do professor ele pode usar o áudio como um tipo de Podcast [30] e ouvir em diversos ambientes. Outro aluno afirma que o uso do celular ajuda a "Traduzir algumas palavras do inglês para português", uma prática interessante que com estratégias adequadas o professor pode contribuir para a construção do conhecimento desse aluno por meio deste uso (construção de frases, busca de palavras, falsos cognatos, etc.). Um uso bastante comum do celular em sala de aula é observado nas aulas de matemática, da qual o aluno infere que " $E u$ uso na aula de matemática" na qual o dispositivo é empregado como calculadora. Infelizmente nos relatos analisados, um aluno informa que utiliza o aparelho "Para filar" também conhecido como "cola", prática não aprovada no âmbito escolar, um dos motivos que algumas escolas e professores não permitem a utilização do celular em sala de aula.

No quesito "Sobre o que você pesquisou?" Como descrito anteriormente o tema para todos os grupos foi "Definições de Calor". Quando questionados como foi a pesquisa "Como foi sua pesquisa?" os alunos destacaram que foi boa e fácil, além de descreverem como ponto positivo da pesquisa que "em 50 minutos deu para concluir toda a pesquisa", alguns destacaram o "acesso rápido" as informações, a possibilidade de ver diversos vídeos tratando o mesmo conteúdo "vimos vários vídeos que falavam sobre calor, o que um não tinha o outro falava.". Para esses alunos a pesquisa "Foi interessante, porque utilizamos o celular como um método diferente de pesquisa em sala de aula" além de afirmarem que "a aula foi diferente e atraiu mais a nossa atenção". Esses alunos descreveram também que tiveram "um pouco de dificuldade pelo fato de ter um celular com wifi mas a não ser isso foi uma boa pesquisa", "a única dificuldade é que a tela do celular é pequena, mais a pesquisa foi tranquilo, consegui encontrar os blogs rápido e estavam bem explicados" e "foi ótimo pois enquanto pesquisava aprendi sobre o assunto. E é mais rápido e fácil." No que diz respeito às dificuldades apresentadas durante a pesquisa
("Houve dificuldade em realizar a atividade?") esses alunos enfatizaram a baixa velocidade da banda larga, principalmente para os grupos que tiveram que pesquisar em vídeos. Um dos alunos que pesquisaram nos blogs destacou as propagandas como ponto negativo na pesquisa, além de mencionar que "você tem que está em um local que pegue bem o wifi". Poucos alunos creditaram ao tamanho da tela do celular como dificuldade em realizar a atividade.

Sobre as fontes pesquisadas ("Qual(is) a(s) fonte(s) pesquisada(s)?"), os grupos exploraram o tema calor em: (1) artigos e blogs disponibilizando os endereços de sua pesquisa: 007blog.net / fisica-maniacos.blogspot.com / oshiman.blogspot.com.br (grupo A1), mundo vestibular / alunosonline.blogspot.com / Artigo: Quanto mais quente melhor (grupo A2), blogdicas.net/o-conceito-do-calor-etemperatura / blogmail.com.br (grupo B1), Caldeira digital (grupo B2). Desses grupos apenas o A2 consultou além dos blogs um artigo da Revista Química Nova na Escola tratando sobre o tema. (2) artigos e vídeos na qual se observou que todos os vídeos foram pesquisados no site do youtube, as fontes consultadas foram: transmissão de calor por condução no youtube (grupo A3), Física Termologia: Calor e Temperatura no youtube (grupo A4), Calor no youtube e na Revista Brasileira do ensino de física, contudo não indicaram qual(is) artigo(s) pesquisado(s) (grupo B3), o grupo B4 pesquisou Calor no youtube justificando que "nós achamos um vídeo no youtube chamado 'calor' e tinha as informações que nós usamos". Embora existam outros sites que esses alunos poderiam consultar os vídeos (teachertube, podomatic, vímeo, Yahoo! vídeo, dailymotion, etc.) eles ficaram restritos em sua busca ao site do youtube. (3) recursos da web 2.0 na qual os grupos A5 e B5 tiveram sua pesquisa direcionada aos inúmeros recursos disponíveis na rede para realizarem a atividade, descrevendo os seguintes endereços: site Cola da web e Wikipédia para o grupo A5 e Wikipédia e no site da FEM Unicamp - aula em pdf do professor Ricardo A. Mazza sobre calor - para o grupo B5. Ademais, destacamos que o acesso por esses alunos às ferramentas da $W e b$ 2.0, descritas anteriormente, não reflete necessariamente em uma interação desses com as ferramentas e consequentemente em uma aprendizagem.

O esquema abaixo (figura 4) expõe uma possível interação por parte do usuário das ferramentas da Web 2.0. Neste esquema a aprendizagem ocorre por meio de páginas da Web 2.0 quando há uma interação entre o usuário (que está acessando a mesma) e os conteúdos. Esses conteúdos construídos, devem ser baseados em pressupostos da Teoria da Flexibilidade Cognitiva [31, 32, 33], afim de propiciar uma aprendizagem flexível para o usuário. 


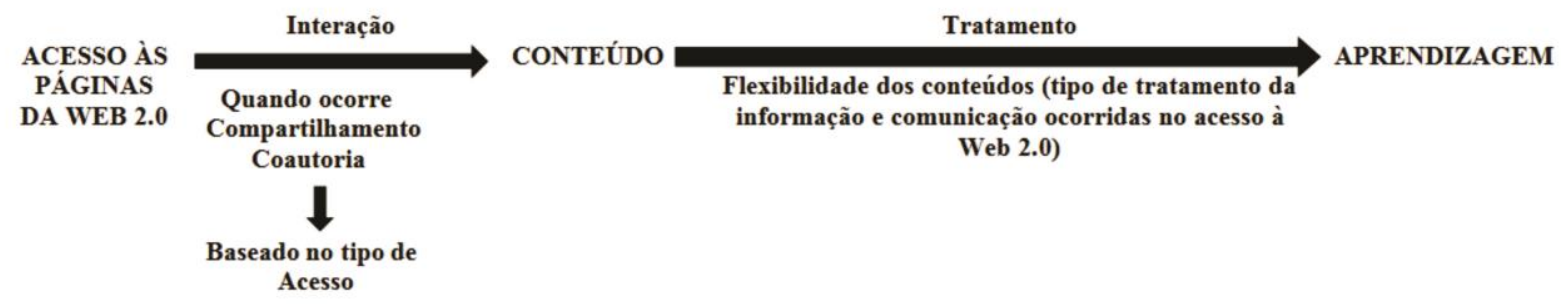

Figura 4: Possível interação do usuário com ferramentas da Web 2.0.

Entendemos que quando o esquema proposto na figura 4 ocorre, observamos, no que se refere à Aprendizagem $2.0[25,26]$, que os alunos tiveram a oportunidade de aprender fazendo (ao construírem o trabalho para ser apresentado para a turma), aprender interatuando (numa possível troca de informações e discussões online entre esses alunos), aprender buscando (na busca efetiva de informações que sejam relevantes ao trabalho solicitado) e aprender compartilhando (quando esses alunos compartilharam não apenas as informações encontradas, mas com os ambientes utilizados - computador, rede de acesso à web, links, entre outras informações). Essa aprendizagem 2.0 foi percebida nos resultados dos questionários, das atividades propostas pelo professor e nos seminários apresentados.

Partindo da premissa dos dados analisados, quando questionados se aprenderam com a pesquisa ("Você aprendeu com sua pesquisa?") 91,48\% acreditam que sim, alguns comentários: "sim, pois enquanto pesquisava aprendi, pois tinha que le o que pesquisava", "Aprendi o significado de calor e o que ele faz com alguns materiais", "Aprendi a diferenciar calor de temperatura", um dos alunos do grupo A4 afirma que "É um modo moderno para os alunos praticarem e pesquisarem, sobre tal assunto é um ótimo estilo de pesquisa", "Aprendi sobre calor sensivel e latente" e "tive que ler e entender para explicar" aqui se observa o fato do aluno ter que ler e entender o assunto para poder explicar para os demais colegas, no momento reservado para as apresentações. Outra resposta que nos chamou a atenção é de que para o aluno do grupo B2 "Foi uma maneira simples e diferente de aprender usando a tecnologia em sala de aula, as aulas diferentes atraem a atenção dos alunos" esta resposta elucida claramente a importância de atividades pedagógicas, não apenas de professores de química, com o uso das TIC no processo de ensino e aprendizagem. Dos alunos que afirmaram não entender com a pesquisa, justificaram ao fato de que "já havia estudado esse assunto ano passado, apenas relembrei", "onde pesquisamos não detalhava muito" e "o calor não só tem um sentido, mas vários", neste trecho o aluno destaca o calor definido de várias formas, possivelmente devido a concepções cotidianas e científicas do tema. Como o objetivo da pesquisa é discutir o tema calor na introdução dos conteúdos da Termoquímica, acreditamos que o professor deve a partir dos conceitos básicos de calor procurar auxiliar o aluno na construção dos conceitos científicos, conforme afirmam Mortimer e Amaral [10].

Os resultados também nos permitiram observar que, na opinião dos alunos ("O celular como ferramenta de aprendizagem, em sua opinião:"), 82,97\% acreditam que o celular pode permitir a aprendizagem em qualquer lugar e $63,82 \%$ admitem que o celular deixa a aula mais interessante. Compreende-se que o uso do celular em aula pode colaborar para pesquisas e trabalhos, bem como para encontrar mais conteúdos que não estão disponíveis nos livros. Apenas $23,4 \%$ responderam que o celular não ajuda a entender o conteúdo. Nesse mesmo sentido, quando questionados sobre o que acharam da pesquisa ("O que você achou de pesquisar com o celular?"), os alunos destacaram: "ótimo, pois você não precisa de um computador e só com o celular você resolve seu proble$m a$ ", este aluno destaca o celular com uma ferramenta que pode ser utilizada na sua aprendizagem, "achei bom, até porque a gente não estava tão preparado pra um trabalho e com a ajuda do celular foi melhor, rápido". É importante ressaltar o que um dos alunos comentou: "Uma experiência muito boa, provou que o celular não é só para falar com os amigos, mas também para me ajudar com os estudos.", aqui se evidencia a importância do celular como uma ferramenta de aprendizagem. Outros alunos salientaram que é uma "boa opção de atividades que requer uma pesquisa mais profunda", que "Achei diferente. Despertou nossa atenção pelo assunto, tornando a aula mais agradável e obtendo melhores resultados.", que "Foi diferente, pois pode-se pesquisar em qualquer lugar" e "Com o celular você faz a pesquisa em poucos minutos evitando de você ficar horas procurando em livros". Ao destacar sua opinião quanto a pesquisa com o celular, um desses alunos afirma que "Utilizar o celular é mais eficiente, para o aluno que sente vergonha em perguntar para o professor. Achei normal, como se eu estivesse pesquisando em casa.". Nota-se que uma das palavras mais mencionadas nas respostas desse questionamento foi "diferente". É concebível que essas respostas relatem ao fato de a abordagem com as tecnologias no 
ensino causem grande impacto quanto ao processo de ensino e de aprendizagem de química.

Do questionário discutido considera-se que as sugestões dos alunos destacam o potencial dos dispositivos móveis, juntamente com a Web 2.0, como uma ferramenta de aprendizagem promissora no ensino.

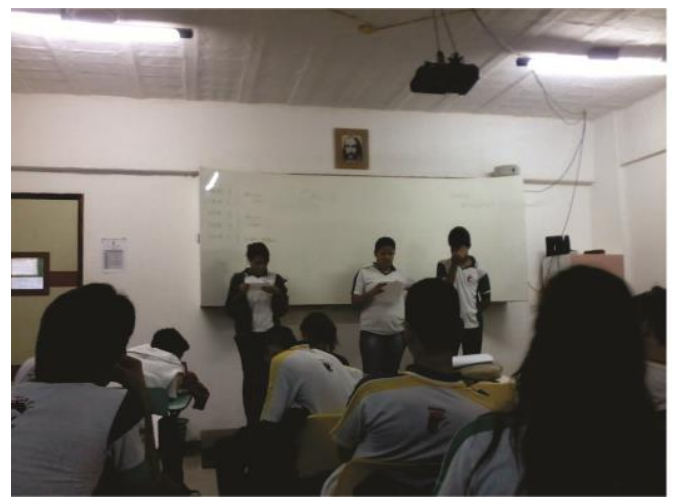

\subsection{Das apresentações dos Seminários}

Após realizarem a atividade com dispositivo móvel, os alunos tiveram um intervalo de 30 minutos para organizarem e apresentarem na forma de seminário os resultados da pesquisa sobre Calor, não foi delimitado tempo para as apresentações, deixando os alunos livres para discutirem sua pesquisa com os demais alunos na sala de aula (figura 5).

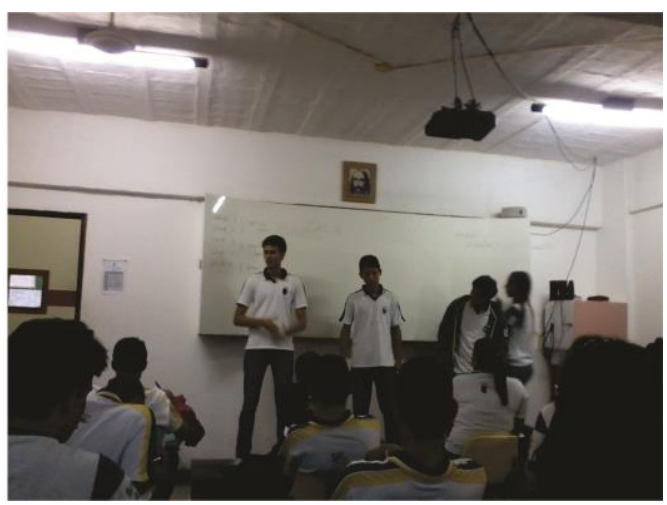

Figura 5: Apresentação dos grupos.

Essas apresentações constituíram, na perspectiva do pesquisador, como atividades construtivistas, tendo em vista que esses alunos durante todo o processo buscaram e criaram suas apresentações mediantes aprendizagens formadas no período de aula.

A aprendizagem e o conhecimento construído durante a atividade dependeram da diversidade de opiniões, pressuposto do Conectivismo [16], na qual esses conectaramse a links sobre o tema abordado e distribuídos dentro de uma rede social, tecnologicamente avançada, reconheceram e interpretaram padrões [16] cônscios da efetivação de suas atividades. Observa-se um caráter conectivista quando confrontados com o aprendizado em ambientes diferentes dos que estamos habituados, esses alunos conceberam uma aprendizagem baseada na rede.

$\mathrm{Na}$ apresentação da pesquisa para a turma, o grupo A1 delineou seu seminário destacando o efeito estufa, exemplos de calor e comparações sobre calor. O grupo A2 discutiu sobre calor enfatizando calor específico, calor sensível, calor latente e diferenças a respeito das concepções de quente e frio. O seminário apresentado pelo grupo A3 descreveu uma experiência sobre a dilatação térmica, gerando entre os alunos dúvidas sobre o fato apresentado. No grupo A4 a apresentação esboçou a definição de temperatura, o equilíbrio térmico e as escalas para medir a temperatura. No grupo A5 que teve sua pesquisa livre, exibiu definições sobre calor e as unidades utilizadas. Delineando sobre a pesquisa o grupo B1 na apresentação de seu seminário elucidou calor, sensações térmi- cas, diferenças sobre calor e temperatura, já o grupo B2 expos apenas uma definição sobre calor. O grupo B3 tratou no seminário calor e resfriamento, calor específico, determinação do calor específico e reações químicas. $\mathrm{O}$ grupo B4 enfatizou que na pesquisa encontrou definições de calor não somente na química, mas também na física e tentou relacionar as "duas" definições de calor existentes. Por fim, o grupo B5 relatou sobre transferência de calor, calor específico e unidade do sistema internacional de medidas (joule).

As apresentações dos grupos relataram, de maneira concisa, os resultados das pesquisas. De fato se concebe que as apresentações dos grupos na segunda parte da atividade, permitiu aos alunos discutirem em sala de aula as definições de calor que encontraram em suas pesquisas utilizando o celular. Como estratégia o professor conduziu esses alunos a reflexão sobre o conteúdo estudado, não sendo uma pesquisa isolada, mas com discussão dos dados observados.

Por fim, cabe ressaltar que o uso de dispositivos móveis em sala de aula permitiu uma relação com o conectivismo, na qual afirma que o conhecimento existe em sistemas acessados pelos indivíduos e não reside exclusivamente na cabeça das pessoas. $\mathrm{O}$ aprendizado consiste na habilidade de construir e passear pelas redes. É comum que os adolescentes estudem conectados a vários sites e dispositivos de comunicação simultaneamente, o que impõe uma forma diferente de relacionamento com a informação e conhecimento. 


\section{Considerações finais}

A produção deste trabalho permitiu apresentar uma experiência pedagógica em que um grupo de alunos trabalharam com algumas ferramentas da Web 2.0 durante um período da disciplina de Química-Física, envolvendo a temática: Calor. A temática escolhida permitiu aos alunos uma diversidade de percepções para o questionamento inicial (Pesquisar definições de calor), além de contribuir para a escolha livre dos alunos. A aplicação do questionário sobre a utilização do celular como ferramenta de aprendizagem e a posterior análise do celular como ferramenta de ensino-aprendizagem de Química, nesse estudo, demonstraram ter um grande potencial da aprendizagem móvel no ensino. A avaliação da utilização do m-learning pelos alunos, possibilitou a identificação de estratégias e habilidades dessa ferramenta para o ensinoaprendizagem.

Admite-se que este trabalho abre uma nova perspectiva sobre as potencialidades da aprendizagem móvel no ensino, em especial Ensino de Química, que pode ser utilizada como uma ferramenta pedagógica e de pesquisa, e que sua utilização não pode ser vista como um substituto de outros recursos. Ao uso do celular em sala de aula acrescentamos dois aspectos fundamentais:

1. Adição (simultaneidade) a outros recursos didáticos como livros, quadro-negro, laboratórios etc.

2. Estratégias planejadas de uso. O sucesso da utilização do m-learning no ensino de química está mais condicionado a forma de utilização do mesmo.

Numa perspectiva construtivista os professores e alunos podem construir seu próprio banco de informações e assumir a responsabilidade pelo gerenciamento das tarefas de aprendizagem. Contudo, é preciso uma visão inovadora que contemple diversas perspectivas de aprendizagem, aproveitando-se das amplas possibilidades comunicativas e informativas das TIC para a concretização de um ensino crítico e transformador de qualidade.

Ainda é muito cedo para tirar conclusões sobre o impacto real que pode ter estratégias envolvendo os dispositivos móveis, pois é evidente que todas suas características são suscetíveis de aplicações ao trabalho diário de professores e estudantes. Entretanto, acredita-se que os resultados alcançados neste trabalho equacionam o potencial educativo da utilização do m-learning, em especial o celular, como ferramenta de ensino-aprendizagem, quer seja de forma introdutória ou de revisão em aulas independente do assunto abordado.

\section{Referências}

[1] F. Freire. Pedagogia da Autonomia: saberes necessários à prática educativa. Paz e Terra, São Paulo, 1996.

[2] B. S. Leite. O uso das tecnologias no Ensino de Ciências: A web 2.0 como ferramenta de aprendizagem. Dissertação de Mestrado em Ensino de Ciências, Universidade Federal Rural de Pernambuco, Fev 2011.

[3] V. M. Kenski. Educação e tecnologias: o novo ritmo da informação. Papirus, Campina, 2007.

[4] C. Coll; C. Monereo. Psicologia da Educação Virtual: Aprender e Ensinar com as Tecnologias da Informação e da Comunicação. Artmed, Porto Alegre, 2010.

[5] M. B. C. Leão. Tecnologias na educação: uma abordagem crítica para uma atuação prática. UFRPE, Recife, 2011.

[6] M. Giordan. Correio e bate-papo: a oralidade e a escrita ontem e hoje. Química Nova na Escola. 8: 07-09, 1998.

[7] M. Giordan. A internet vai à escola: domínio e apropriação de ferramentas culturais. Educação e Pesquisa. 31(1): 57-78, 2005

[8] M. Prensky. Digital natives, digital immigrants. On the Horizon, 9(5): 01-06, 2001.

[9] R. J. Oliveira; J. M. Santos. A Energia e a Química. Química Nova na Escola. 8:19-22, 1998.

[10] E. F. Mortimer; L. O. F. Amaral. Quanto mais quente melhor: calor e temperatura no ensino de termoquímica. Química Nova na Escola. 7:3034, 1998

[11] T. O'Reilly. What is Web 2.0? Design patterns and business models for the next generation of software. 2005. http://www.oreillynet.com/pub/a/oreilly/tim/new s/2005/09/30/what-is-web-20.html. Out. 2014.

[12] A. Primo. O aspecto relacional das interações na Web 2.0. In: Anais do XXIX Congresso Brasileiro de Ciências da Comunicação, Brasília, páginas 01-15, 2006.

[13] C. R. Cobo; H. K. Pardo. Planeta Web 2.0. Inteligencia colectiva o médios fast food. BarcelonaMéxico, Grup de Recerca d'Interaccions Digitals, Universitat de Vic. Flacso México, 2007.

[14] J. Piaget. O diálogo com a criança e o desenvolvimento do raciocínio. Scipione, São Paulo, 1997.

[15] S. Papert. Constructionism: A New Opportunity for Elementary Science Education. Cambridge, Massachusetts Institute of Technology, Media Laboratory, Epistemology and Learning Group, 1986. 
[16] G. Siemens. Connectivism: A Learning Theory for the Digital Age. Instructional Technology and Distance Education, 2(1):3-10, 2004.

[17] G. Siemens. Connectivism: Learning Theory or Pastime for the Self-Amused? 2006. http://www.elearnspace.org/Articles/connectivis m_self-amused.htm. Out. 2014.

[18] T. Anderson; J. Dron. Three generations of distance education pedagogy. International Review of Research in Open and Distance Learning, 12(3):80-97, 2011.

[19] J. Mattar. Web 2.0 e Redes Sociais na Educação. Artesanato Educacional, São Paulo, 2013.

[20] P. L. P. Rau; Q. Gao; L. M. Wu. Using mobile communication technology in high school education: Motivation, pressure, and learning performance. Computers \& Education. 50(1): 0122, 2008.

[21] M. Wang; R. Shen; D. Novak; X. Pan. The impact of mobile learning on students' learning behaviours and performance: Report from a large blended classroom. British Journal of Educational Technology, 40(4): 673-695, 2009.

[22] D. Dochev; I. Hristov. Mobile Learning Applications - Ubiquitous Characteristics and Technological Solutions. Bulgarian Academy Of Sciences Cybernetics And Information Technologies, 6(3):63-74, 2006.

[23] V. F. Bartholo; M. A. Amaral; M. I. Cagnin. Uma Contribuição para a Adaptabilidade de Ambientes Virtuais de Aprendizagem para Dispositivos Móveis. Revista Brasileira de Informática na Educação, 17(2): 36-47, 2009.

[24] M. Prensky. But the screen is Too Small... Sorry, "Digital Immigrants"- Cell Phones - Not Computers - Are The Future Of Education. 2003. http://www.marcprensky.com/writing/Prensky\% $20-$ $\% 20$ But $\% 20$ the $\% 20$ screen $\% 20$ is $\% 20$ too $\% 20$ sm all.pdf, Out. 2014.

[25] S. Johnson. Emergence. The connected lives of ants, brains, cities and software. Penguin Books, London, 2001.

[26] B. A. Lundvall. The University in the Learning Economy. DRUID Working Papers, 2(6): 01-19, 2002.

[27] M. Lüdke; M. E. D. A. André. Pesquisa em educação: abordagens qualitativas. E.P.U., São Paulo, 2012.

[28] M. R. Barro; J. Q. Ferreira; S. L. Queiroz. Blogs: aplicação na educação em Química. Química Nova na Escola. 30: 10-15, 2008.

[29] J. Ferrés. Vídeo e Educação. Artmed, Porto Alegre, 1996.

[30] B. S. Leite; M. B. C. Leão; S. A. Andrade. Videocast: uma abordagem sobre pilhas eletrolíticas no ensino de Química. Revista tecnologias na Educação. 2: 01-11, 2010.

[31] R. Spiro; W. Vispoel; J. G. Schmitz; A. Samarapungavan; A. E. Boerger. Knowledge Aquisition for Application: Cognitive Flexibility and Transfer in Complex Content Domains. In B. C. Britton e S. M. Glynn (eds.), Executive Control in Processes in Reading. New Jersey: Lawrence Erlbaum Associates, páginas 177-199, 1987.

[32] R. Spiro; J. Jehng. Cognitive flexibility and hypertext: Theory and technology for the nonlinear and multidimensional traversal of complex subject matter. In D. Nix; R. Spiro (eds.), Cognition, Education, and Multimedia. Hillsdale, NJ: Erlbaum, páginas 163-205, 1990.

[33] R. Spiro; P. J. Feltovich; M. Jacobson; R. Coulson. Cognitive Flexibility, Constructivism, and Hypertext: random access instruction for advanced knowledge acquisition in ill-structured domains. Educational Technology, 31(5), 24-33, 1991. 